\section{Temporomandibular Joint Arthritis in Pediatric Sjögren Disease and Sarcoidosis}

\section{To the Editor:}

Arthritis of the temporomandibular joint (TMJ) is a well recognized entity in patients with juvenile idiopathic arthritis (JIA). It is usually painless and even minor radiographic changes of the TMJ have been associated with disruption in mandibular growth and a number of other craniofacial changes ${ }^{1}$. Recently, magnetic resonance imaging (MRI) evaluations have proven to have much greater sensitivity to detect arthritis compared to ultrasound, and placed the prevalence of TMJ arthritis in this population between $63 \%$ and $75 \%{ }^{2,3}$. Due to this high prevalence, patients with JIA frequently receive contrast-enhanced MRI scans of the TMJ as a standard evaluation for arthritis in several clinical centers.

There are other rheumatologic diseases that can also present with TMJ inflammation [e.g., sarcoidosis, Sjögren disease, mixed connective tissue disease (MCTD) $]^{4,5,6}$, but the prevalence is less known. During the course of clinical care at the Pediatric Rheumatology Clinic at Children's Hospital of Alabama (Birmingham, AL, USA), several non-JIA arthritis patients have presented with symptoms and/or signs consistent with TMJ disease and were subsequently evaluated by MRI for TMJ arthritis. We describe the MRI findings of TMJ arthritis in these patients.

The protocol for this study was approved by the University of Alabama at Birmingham Institutional Review Board. Between September 2007 and December 2010, 75 patients with various non-JIA arthritis-associated rheumatic diseases (34 with Sjögren disease, 19 sarcoidosis, 22 MCTD) were identified by electronic medical records and studied. Diagnoses were based on the expert opinion of one of the 3 pediatric rheumatologist authors, in some cases based on strong clinical suspicion when lacking biopsy evidence. Acute TMJ arthritis was defined as the presence of effusion or synovial enhancement, and chronic disease as synovial thickening or evidence of bony changes (e.g., condylar flattening or erosions, both typical of TMJ arthritis). Electronic medical records, including clinical progress notes, laboratory results, and TMJ imaging reports of the 75 patients, were thoroughly examined and results documented.

A total of 18 (25\%) non-JIA patients received MRI of the TMJ during the study period, and $89 \%$ of those had documented arthritis elsewhere. Of the 18 MRI evaluations, 7 (39\%) showed evidence of TMJ arthritis. Ten of $34(29 \%)$ patients with Sjögren disease were screened for TMJ arthritis by MRI; 4/10 had positive MRI evidence of TMJ arthritis. Five of 19 (26\%) sarcoidosis patients were screened by MRI; $3 / 5$ had positive MRI evidence of TMJ arthritis. Three of $22(13.6 \%)$ MCTD patients were screened by MRI; 0/3 had positive MRI evidence of TMJ arthritis.

The characteristics of the patients are shown in Table 1. Subjective symptoms were present in 6/18 (33\%), and 13/18 (72\%) had clinical signs of TMJ dysfunction. The precise indication for MRI for 2 patients could not be deduced from clinical records. Common subjective symptoms noted were pain and locking of the jaw. Common clinical findings included jaw deviation during opening and reduced maximal interincisor distance. Clinical characteristics for the 7 patients with radiographic evidence of TMJ arthritis (4 with Sjögren, 3 with sarcoidosis) are shown in Table 2. Only 2/7 (29\%) of the patients found to have TMJ arthritis had subjective symptoms. The remaining $5 / 7(71 \%)$ had a positive clinical finding (jaw deviation). None of the patients with abnormal MRI had both subjective symptoms and positive clinical findings. Concurrent peripheral arthritis was present on examination in 6/7 (86\%).

Recent studies have concluded that MRI is the most sensitive ${ }^{2,3}$ and specific $^{7}$ method for detecting TMJ arthritis in children with chronic peripheral arthritis. All patients in our study with non-JIA childhood arthritis and suspected TMJ disease were evaluated by this imaging method. Signs or symptoms of TMJ arthritis were found in all 7 patients with MRI-confirmed TMJ arthritis. This highlights why it is appropriate to look for masticatory muscle tenderness, restricted maximal interincisor distance, and deviation in mouth opening ${ }^{4}$. For children with JIA, the most common subjective symptoms noted in patients with TMJ arthritis are pain at rest, crepitation, swelling, and clicking ${ }^{8}$. While the sensitivity of symptoms and clinical findings may be low, the risk of overlooking this diagnosis in a child can be devastating, and it is therefore important to be cautious about any deviation from normal in a maxillofacial examination. Perhaps more concerning is the fact that in some studies the great majority of JIA patients with TMJ arthritis were asymptomatic ${ }^{3}$. This suggests that perhaps all children with chronic arthritis should be evaluated for TMJ arthritis.

Our data show that TMJ arthritis can be present in children with non-JIA inflammatory rheumatic diseases with chronic joint involvement, possibly with lower prevalence. Moreover, TMJ arthritis can be similarly destructive. Thus, a maxillofacial screening examination should be completed at each visit of a patient with non-JIA childhood arthritis, and subjective symptoms or clinical findings should prompt physicians to consider a TMJ MRI for further evaluation. We are currently evaluating the potential benefit of intraarticular triamcinolone hexacetonide injections of the TMJ in this cohort of patients with non-JIA chronic arthritis.

EMILY T. FAIN, BS; GEORGE P. ATKINSON, PhD; PETER WEISER, MD, Assistant Professor; TIMOTHY BEUKELMAN, MD, MSCE, Assistant Professor; RANDY Q. CRON, MD, PhD, Professor, Children's Hospital of Alabama, Department of Pediatrics, Division of Pediatric Rheumatology, University of Alabama at Birmingham, Children's Park Place, Ste. 210, 1601 4th Avenue South, Birmingham, Alabama 35233, USA. Address correspondence to Dr. Cron; E-mail: rcron@peds.uab.edu

\section{REFERENCES}

1. Billiau AD, Hu Y, Verdonck A, Carels C, Wouters C. Temporomandibular joint arthritis in juvenile idiopathic arthritis: prevalence, clinical and radiological signs, and relation to

Table 1. Characteristics of patient groups requiring MRI of temporomandibular joint.

\begin{tabular}{lccc}
\hline Characteristic & $\begin{array}{c}\text { Sjögren, } \\
\mathrm{n}=10\end{array}$ & $\begin{array}{c}\text { Sarcoidosis, } \\
\mathrm{n}=5\end{array}$ & $\begin{array}{c}\text { MCTD, } \\
\mathrm{n}=3\end{array}$ \\
\hline Sex, M/F & $1 / 9$ & $4 / 1$ & $1 / 2$ \\
Age, mean yrs (range) & $13.5(4-19)$ & $11(9-16)$ & $13(13)$ \\
Race, White/African American & $5 / 5$ & $3 / 2$ & $3 / 0$ \\
Peripheral arthritis present $\%$ & 100 & 80 & 100 \\
Symptoms, no. patients $(\%)$ & $4(40)$ & $1(20)$ & $1(33)$ \\
Locking & $1(10)$ & - & - \\
Pain & $3(30)$ & $1(20)$ & $2(33)$ \\
Clinical findings, no. of patients $(\%)$ & $7(70)$ & $4(80)$ & $2(67)$ \\
Reduced MIO & $2(20)$ & - & $2(67)$ \\
Asymmetric opening & $7(70)$ & $4(80)$ & \\
\hline
\end{tabular}

MCTD: mixed connective tissue disease; MIO: maximal interincisor opening. 
Table 2. Characteristics of patients with MRI-confirmed TMJ arthritis.

\begin{tabular}{|c|c|c|c|c|c|c|c|}
\hline Patient & $\begin{array}{l}\text { Age, yrs, } \\
\text { sex }\end{array}$ & Race & Diagnosis & Serology & $\begin{array}{c}\text { Peripheral } \\
\text { Arthritis, }(\mathrm{Y} / \mathrm{N})\end{array}$ & Indication for MRI & Original MRI Results \\
\hline 1 & $17 \mathrm{~F}$ & $\mathrm{AA}$ & Sjögren & $\begin{array}{l}\text { ANA 1:640, } \\
\text { speckled, } \\
\text { SSA +, RF+ }\end{array}$ & $\mathrm{Y}$ & Asymmetric opening & Mild Bi TMJ arthritis \\
\hline 2 & $13 \mathrm{~F}$ & AA & Sjögren & $\begin{array}{l}\text { ANA 1:80, } \\
\text { speckled, } \\
\text { SSA+, RF-, } \\
\text { HLA-B27- }\end{array}$ & $\mathrm{Y}$ & TMJ pain & $\begin{array}{c}\text { Flattening of mandibular condyle, } \\
\text { Bi synovial enhancement }\end{array}$ \\
\hline 3 & $14 \mathrm{~F}$ & AA & Sjögren & $\begin{array}{l}\text { ANA 1:640, } \\
\text { speckled, } \\
\text { SSA+, RF- }\end{array}$ & $\mathrm{Y}$ & Asymmetric opening & Bi TMJ synovial enhancement \\
\hline 4 & $11 \mathrm{~F}$ & $\mathrm{~W}$ & Sjögren & $\begin{array}{c}\text { ANA 1:1280, } \\
\text { speckled, } \\
\text { SSA+, RF- }\end{array}$ & Y & Asymmetric opening & Bi TMJ synovial enhancement \\
\hline 7 & $14 \mathrm{M}$ & $\mathrm{W}$ & $\begin{array}{l}\text { Sarcoidosis } \\
\text { (by LN } \\
\text { biopsy) }\end{array}$ & $\begin{array}{c}\text { ANA-, ACE 49, } \\
\text { lysozyme 7.5, } \\
\text { HLA-B27- }\end{array}$ & $\mathrm{N}$ & TMJ pain & $\begin{array}{l}\text { Bi TMJ fluid, increased } \\
\text { enhancement } \mathrm{R} \text { TMJ }\end{array}$ \\
\hline
\end{tabular}

* Reference ranges: ACE 13-100; lysozyme 4.0-10.3. AA: African American; ACE: angiotensin-converting enzyme; ANA: antinuclear antibody; Bi: bilateral; LN: lymph node; R: right; RF: rheumatoid factor; SSA: Sjögren syndrome A antibody; TMJ: temporomandibular joint; W: white.

dentofacial morphology. J Rheumatol 2007;34:1925-33.

2. Muller L, Kellenberger CJ, Cannizzaro E, Ettlin D, Schraner T, Bolt IB, et al. Early diagnosis of temporomandibular joint involvement in juvenile idiopathic arthritis: a pilot study comparing clinical examination and ultrasound to magnetic resonance imaging. Rheumatology 2009;48:680-5.

3. Weiss PF, Arabshahi B, Johnson A, Bilaniuk LT, Zarnow D, Cahill $\mathrm{AM}$, et al. High prevalence of temporomandibular joint arthritis at disease onset in children with juvenile idiopathic arthritis, as detected by magnetic resonance imaging but not by ultrasound. Arthritis Rheum 2008;58:1189-96.

4. Helenius LM, Hallikainen D, Helenius I, Meurman JH, Kononen M, Leirisalo-Repo M, et al. Clinical and radiographic findings of the temporomandibular joint in patients with various rheumatic diseases. A case-control study. Oral Surg Oral Med Oral Pathol Oral Radiol Endod 2005;99:455-63.
5. List T, Stenstrom B, Lundstrom I, Dworkin SF. TMD in patients with primary Sjogren syndrome: a comparison with temporomandibular clinic cases and controls. J Orofac Pain 1999;13:21-8.

6. Schwartz HC. Sarcoid temporomandibular arthritis. Oral Surg Oral Med Oral Pathol 1981;52:588-90.

7. Tzaribachev N, Fritz J, Horger M. Spectrum of magnetic resonance imaging appearances of juvenile temporomandibular joints (TMJ) in non-rheumatic children. Acta Radiol 2009;50:1182-6.

8. Twilt M, Mobers SM, Arends LR, ten Cate R, van Suijlekom-Smit L. Temporomandibular involvement in juvenile idiopathic arthritis. J Rheumatol 2004;31:1418-22.

J Rheumatol 2011;38:10; doi:10.3899/jrheum.110080 